\title{
Pemantapan Tes Minat Bakat Di Kecamatan Medan Johor
}

\section{Mawaddah Nasution ${ }^{1}$}

${ }^{1}$ Pendidikan Islam Anak Usia Dini, Universitas Muhammadiyah Sumatera Utara Jl Kapten Mukhtar Basri No 3 Medan, Indonesia, 20238

*Email koresponden: mawaddahnst@umsu.ac.id

\section{ARTICLE INFO \\ Article history \\ Received: 05 Jul 2021 \\ Accepted: 12 Des 2021 \\ Published: 31 Des 2021}

\section{Kata kunci:}

Intelligensi;

Remaja;

Tes minat bakat.

\section{Keyword: \\ Aptitude test; \\ Intelligence; \\ Teenager.}

\begin{abstract}
A B S T R A K
Background: Banyak remaja yang kebingungan untuk melanjutkan pendidikan ke jenjang selanjutnya, hal ini menjadi salah satu alasan Kegiatan Pengabdian Kepada Masyarakat ini dilakukan. Banyaknya para remaja yang putus sekolah dan masih bingung dalam menentukan minat dan bakatnya dalam menentukan jurusan di sekolah, membuat pengabdian ini dirasa penting bagi para remaja yang berada di lingkungan X Kelurahan Suka Maju Kecamatan medan Johor. Tujuan dari Pengabdian Masyarakat ini membantu para remaja di lingkungan X Kelurahan Suka Maju Kecamatan Medan Johor dalam menentukan taraf intelligensinya mengarahkan minat dan bakatnya dalam menentukan jurusan di sekolah. Pengabdian ini bekerjasama dengan dua Mitra yaitu kepala lingkungan X kelurahan Suka maju Kecamatan Medan Johor dan Remaja Masjid Assyafiiyah dengan jumlah peserta 20 orang. Metode: Memberikan pengarahan tentang intelligensi dan minat bakat, kaitan antara intelligensi dan minat bakat remaja, kemudian melaksanakan tes intelligeni dan minat bakat kepada peserta. Hasil: Para remaja dapat mengetahui taraf intelligensi mereka beserta minat dan bakat yang mereka miliki. Berdasarkan temuan yang terjadi di lapangan hampir seluruh peserta belum pernah mengikuti tes intelligensi maupun tes minat bakat, dan belum mengerti kemana arah minat dan bakat mereka. Kesimpulan: Para remaja dapat mengetahui taraf intelligensi mereka beserta arah minat dan bakatnya. Selain itu mereka juga dapat menentukan jurusan yang akan mereka ambil pada jenjang berikutnya (SMA) di bangku sekolah.
\end{abstract}

\section{A B S T R A C T}

Background: Many teenagers are confused about continuing their education to the next level. This is one of the reasons why this Community Service Activity was carried out. The number of teenagers who drop out of school and are still confused in determining their interests and talents in determining majors at school makes this service important for teenagers in the $X$ neighbourhood of Suka Maju Village, Medan Johor District. The purpose of this Community Service is to help teenagers in the X Suka Maju Village, Medan Johor Subdistrict, in determining their level of intelligence directing their interests and talents in determining majors at school. This service collaborates with two partners, namely the head of the X neighbourhood of Suka Maju sub-district, Medan Johor sub-district and the Youth of the Assyafiiyah Mosque, with a total of 20 participants. Methods: Guide intelligence and talent interests, the relationship between intelligence and talent interests of adolescents, then carry out intelligence and talent interest tests to participants. Results: Teenagers can find out their level of intelligence and their interests and talents. Based on the findings that occurred in the field, almost all of the participants had never taken an intelligence test or an interest-aptitude test. They did not understand where their interests and talents were headed. Conclusion: Teenagers can find out their level of intelligence and the direction of their interests and talents. In addition, they can also determine the majors they will take at the next level (SMA) in school. 


\section{PENDAHULUAN}

Pendidikan adalah hal paling mendasar dan penting bagi kelangsungan individu, dengan adanya pendidikan individu diharapkan dapat memahami sesuatu yang baru dalam hidup dan berprilaku dengan baik. Pendidikan merupakan sesuatu yang membedakan manusia dengan yang lainnya, karena manusia merupakan makhluk yang derajatnya paling tinggi di muka bumi ini. Untuk mendapatkan pendidikan seseorang dapat belajar dimana saja, baik formal maupun informal (Nurzannah, Akrim, 2015), namun untuk mendapatkan penyetaraan dalam pendidikan, individu harus menempuh pendidikan di sekolah formal. Sayangnya banyak diantara para remaja khususnya yang ada di Lingkungan X Kelurahan Suka Maju, Kecamatan Medan Johor tidak melanjutkan pendidikannya, hal ini disebabkan oleh berbagai alasan, salah satunya kurangnya minat belajar anak yang disebabkan pengaruh lingkungan yang kurang baik, banyak dari para remaja tersebut yang tidak melanjutkan pendidikan mereka karena masalah ekonomi, dan karena ketidakpahaman mereka akan melanjutkan ke jenjang pendidikan selanjutnya (Sitepu, 2010).

Sebagian dari remaja yang berada di lingkungan tersebut tidak mengetahui taraf intelligensi dan minat bakat mereka, sehingga sulit dalam menentukan jurusan di sekolah. Selama ini belum ada upaya yang dilakukan oleh masyarakat setempat guna mengedukasi anak-anak mereka tentang intelligensi dan minat bakat. Belum ada pihak tertentu yang melaksanakan kegiatan sosialisasi kepada para remaja di lingkungan $X$ untuk membuka wawasan mereka tentang pentingnya pendidikan yang mereka tempuh, dan bagaimana mengetahui taraf intelligensi serta minat dan bakat mereka dalam menentukan jurusan yang nantinya akan mereka pilih di jenjang sekolah lanjut (Anastasi, 2007).

Lubis, (2008) mengemukakan bahwa inteligensi adalah kemampuan untuk memecahkan masalah, atau menciptakan suatu produk dalam berbagai macam setting dan dalam situasi nyata. Dengan memahami intelligensi, individu memahami sejauh mana kemampuan yang dimilikinya. Berdasarkan wawancara yang dilakuakan kepada para remaja, faktanya mereka masih asing dengan tes intelligensi dan minat bakat, dan sebelumnya tidak pernah mengetahui tentang hal ini apalagi mengikuti tesnya.

Masyarakat yang ada di Lingkungan X Kecamatan Medan Johor mayoritas berstatus sosial ekonomi menengah bawah. Penghasilan keluarga mereka di dapat dari berjualan barang bekas (spearpat sepeda motor maupun mobil). Sebagian bekerja serabutan, buruh, pedagang keliling, dan menjadi asisten rumah tangga. Adapun yang menjadi mitra dalam kegiatan ini yaitu kepala Lingkungan X Kecamatan Medan Johorr dan Remaja Masjid Assyafiiyah. Dengan kondisi keluarag yang seperti itu sangat mempengaruhi kualitas pendidikan bagi anak-anaknya.

Berdasarkan fakta dan observasi yang telah dilakukan sebelumnya, maka kegiatan ini ditujukan sebagai sarana edukasi bagi para remaja khususnya dalam hal pendidikan. Agar mereka lebih memprioritaskan pendidikan, memiliki semangat dalam belajar, dapat menentukan taraf intelligesi dan minat bakat mereka untuk lebih memudahkan dalam memilih jurusan dalam jenjang Sekolah Menengah Atas (SMA).

\section{MASALAH}

Adapun permasalahan yang ditemukan di Lingkungan X Kecamatan Medan Johor yaitu banyak dari mereka tidak melanjutkan Pendidikan ke tahap berikutnya, yang mana hal ini disebabkan karena pergaulan yang kurang baik di sekitar tempat tinggal mereka. Kemudian permasalahan ekonomi keluarga yang membuat remaja tidak dapat melanjutkan sekolah, dan kurangnya pemahaman mereka dalam menentukan peminatan di sekolah dalam memilih bidang 
ilmu sosial ataupun eksakta, karena kebanyakan dari mereka hanya ikut-ikutan teman saja. Belum lagi pola asuh orangtua yang jug aberdampak bagi perkembangan anak (Nasution \& Sitepu, 2018).

Dari penjelasan diatas, maka dapat disimpulkan bahwa permasalahan mitra dapat dijabarkan seperti berikut :

1. Masih banyak para remaja yang tidak mengetahui arah minat dan bakat yang ada pada dirinya, tidak paham akan cita-cita yang ingin diarihnya.

2. Ketidakpahaman para remaja dalam menentukan peminatan di sekolah dalam memilih bidang ilmu sosial ataupun eksakta untuk Sekolah Menengah Atas (SMA), karena kebanyakan dari mereka hanya ikut-ikutan teman saja.

3. Beberapap anak terindikasi malas sekolah, lingkungan yang kurang baik yang salah satunya disebabkan karena ketidaktahuan mereka tentang minat dan bakatnya kearah mana kurangnya kontrol orangtua dalam mendampingi anak belajar, dan hal ini perlu mendapatkan edukasi.

4. Alternatif yang ditawarkan adalah dengan menyelenggarakan kegiatan tes minat bakat, sehingga diharapkan mereka memiliki pemahaman dan mendapatkan gambaran intellegensi serta kemana arah minat dan bakat mereka yang sesuai dengan kemampuan yang dimilikinya.

\section{METODE PELAKSANAAN}

Metode pelaksanaan dalam Program Kemitraan Masyarakat ini yatu dilakuakn dengan cara menjelaskan tentang intelligensi, mulai dari definisi, scor IQ, minat bakat, fungsi dari tes intelligensi dan tes minat bakat dan sebagainya. Untuk mendukung tercapainya solusi yang ditawarkan, maka ada beberapa tahapan yang harus dilakukan yaitu:

1) Tahap Awal

Setelah proposal ini dinyatakan lolos oleh LP2M UMSU pada bulan Maret 2021, maka tim akan menyusun beberapa tahapan awal sebagai berikut:

a) Melakukan koordinasi dengan Kepala Lingkungan X Kelurahan Suka Maju Kecamatan Medan Johorr dan ketua Remaja Masjid Assyafiiyah dan menjelaskan tentang rencana kegiatan yang akan dilakukan.

b) Merancang jadwal kegiatan yang terintegrasi antara tim dengan waktu yang dimiliki para peserta.

c) Menseleksi peserta yang akan dijadikan peserta dalam kegiatan ini yaitu remaja yang sedang duduk dibangku kelas III Sekolah Menengah Pertama (SMP)

2) Tahap Pelaksanaan

Pelaksanaan Program Kemitraan Mayarakat ini dilakukan dengan tahapan sebagai berikut:

a) Melakukan sosialisasi kepada para remaja mengenai tes intelligensi dan tes minat bakat.

b)Menjelaskan proses, instruksi dan tahapan yang akan dilakukan dalam tes.

c) Mulai menyajikan tes intelligensi dan tes minat bakat hingga selesai.

d) Menskoring dan menganalisa hasil tes dari peserta, kemudian membuat laporan tertulis mengenai hasil tes yang telah dilaksanakan.

3) Tahap Akhir

Di akhir sesi ini, akan di evaluasi kegiatan yang telah dijalankan dalam PKM ini, yaitu berupa output scor IQ. Dimana skor IQ ini diinterpretasikan dalam uraian kemampuan anak. Dari hasil tes intelligensi dan skor IQ dapat dilihat kemampuan dan arah bakat minatnya untuk selanjutnya menentukan jurusan yang akan mereka ambil di SMA. 


\section{HASIL DAN PEMBAHASAN}

Sebelum melakukan kegiatan ini, tim terlebih dahulu mengobservasi dan melakukan wawancara dengan salah satu mitra yaitu kepala Lingkungan X Kelurahan Suka Maju Kecamatan Medan Johorr. Dari hasil wawancara dan observasi tersebut, di dapat data bahwa banyak diantara anak remaja yang berada di lingkungan tersebut, malas sekolah, tidak melanjutkan pendidikan mereka, buruknya pergaulan yang terjadi di lingkungan tersebut, banyak dari anak remaja yang sekolah hanya sekedar ikut-ikutan temannya saja, namun tidak mengerti tujuan yang nantinya akan dicapai. Padahal Pendidikan sangat penting bagi kelangsungan hidup manusia (Fanreza, 2016). Sebagaimana yang disampaikan oleh Ma'ruf \& Ma'ruf, (2019), bahawa pendidikan merupakan sesuau yang sangat mendasar bagi semua umat, dengan memiliki Pendidikan seseorang mampu membeddakan mana yang benar dan salah. Melihat kemampuan arah dan minat dipengaruhi oleh intelligensi (Nur'aeni, 2012), maka dari itu kebutuhan yang dinilai penting saat ini adalah memberikan tes intelligensi kepada anak remaja, sebagai salah satu acuan untuk mendapatkan gambaran kemampuannya.

Melihat permasalahan yang ada di Lingkungan X Kelurahan Suka Maju Kecamatan Medan Johorr membuat tim sepakat untuk mengadakan perubahan mindset atau pemahaman kepada para remaja khususnya untuk meneruskan pendidikan mereka ke tahap selanjutnya. Bukan hanya sekedar ikut-ikutan teman atau karena perintah orangtua. Mereka yang dijadikan target program ini adalah para remaja yang saat ini berada di bangku sekolah menengah pertama (SMP) kelas III, dengan harapan ketika mereka akan melanjutkan pendidikannya ke SMA, mereka tidak kebingungan dalam menentukan jurusan yang nantinya mereka ambil. Saat ini pemilihan jurusan dilakukan pada saat awal masuk di SMA, untuk itu remaja perlu mengetahui taraf intelligensi serta minat dan bakat mereka agar pendidikan yang mereka jalankan nantinya sesuai, bukan karena keterpaksaan ataupun sekedar ikut-ikutan teman saja, karena pada dasarnya remaja cenderung mengikut teman sebaya (Hurlock, Elizabeth, 1995). Berikut dokumentasi yang dilakukan pada saat tes keitan berlangsung.

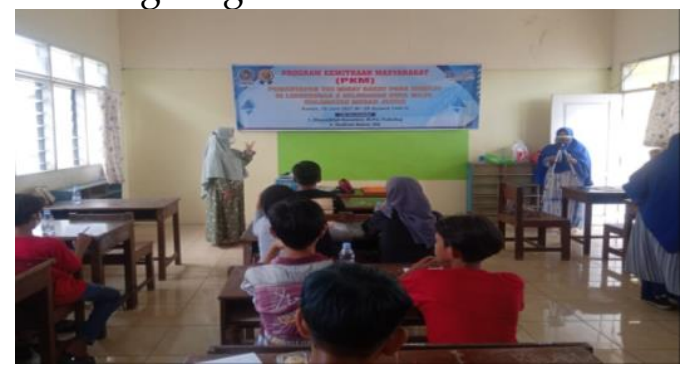

Gambar 1. Pengenalan Program PKM kepada Remaja di Lingkungan X

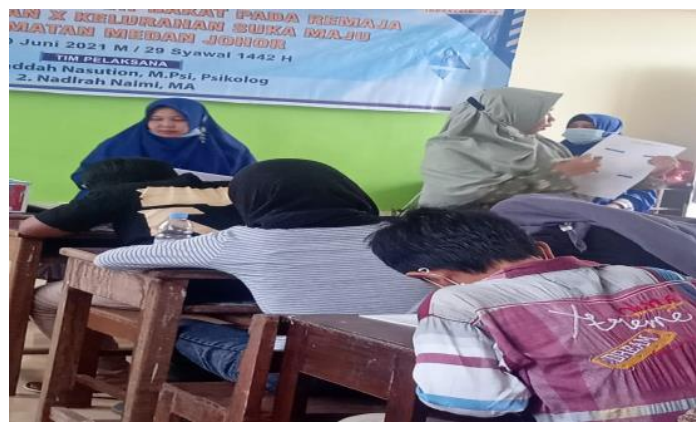

Gambar 2. Tim Menjelaskan Sistematika Pengerjaan Tes

Adapun keunggulan dari diadakannya kegiatan ini yaitu sebagian besar remaja dapat mengetahui taraf intelligensi mereka serta mengetahui kemana arah minat dan bakat yang mereka miliki, dengan mengetahui hal tersebut setidaknya mereka memiliki gambaran tentang 
pendidikan yang akan mereka jalani selanjutnya, dapat mengarahkan hobi mereka sesuai dengan minat dan bakat yang mereka punya (Fatmawaty, 2017). Namun kelemahannya banyak dari remaja yang kurang mempersiapkan diri untuk menjalani tes, sehingga masih didapati yang kurang serius dalam menjalani tes.

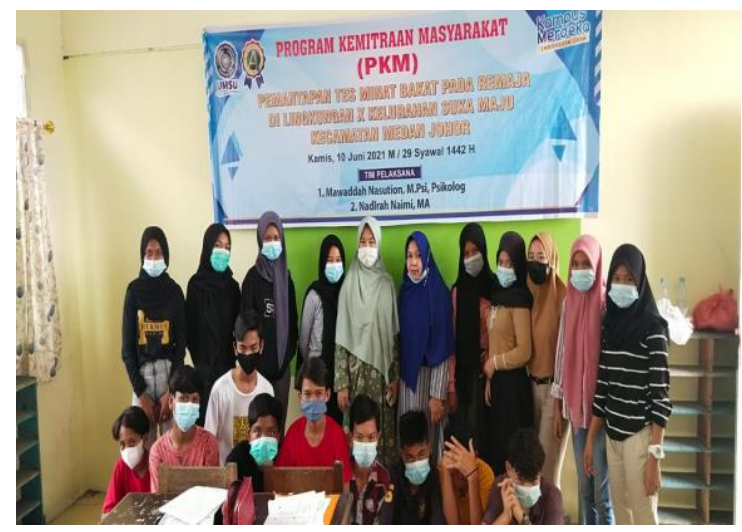

Gambar 3. Foto bersama setelah selesai kegiatan

Dalam pelaksanaan kegiatan ini sebenarnya tidak mengalami kendala yang berarti, hanya saja dalam pengkoordinasian peserta kurang teratur. Ada peserta yang tidak dapat hadir dikarenakan jadwalnya bersamaan dengan kegiatan yang dilakukan. Hasil tes yang didapat anak bervariasi, ada yang rata-rata, diatas rata-rata, dan ada juga yang dibawag rata-rata. Hasil tes ini akan berdampak pada kemampuan anak dalam menentukan arah minat dan bakatnya dalam melanajutkan pendidikannya.

\section{KESIMPULAN}

Dengan diadakannya kegiatan Program Kemitraan Masyarakat ini bagi para remaja yang berada di Lingkungan X Kelurahan Suka Maju Kecamatan Medan Johor, diharapkan mereka dapat memahami apa yang dimaksud dengan tes intelligensi dan tes minat bakat. Mereka dapat mengetahui taraf intelligensi, minat dan bakat mereka lebih kearah mana. Dari hasil tes yang mereka peroleh, mereka diberikan pandangan dan arahan dari tim Ahli (Psikolog) untuk mengambil keputusan/Langkah yang sesuai dengan kemampuan yang mereka miliki. Agar mereka tidak lagi mengalami kebingungan dalam menentukan pilihannya dalam mengambil jurusan dalam jenjang pendidikan selanjutnya. Mereka dapat memutuskan sendiri pilihannya tanpa harus ikut-ikutan teman atau kehendak orangtuanya. Program seperti ini sangat dibutuhkan bagi masyarakat yang tinggal di Lingkungan X Kelurahan Suka Maju Kecamatan Medan Johor, baik itu remaja, anak-anak, maupun orangtua. Mengingat masih banyaknya permasalahan yang terjadi di daerah teresbut, untuk selanjutnya tim tertarik untuk mengadakan edukasi bagi para orangtua dalam mensupport pendidikan anak-anak mereka.

\section{UCAPAN TERIMA KASIH}

Ribuan Terima kasih kami ucapkan kepada LP2M UMSU yang bersedia mendukung kegiatan PKM ini. Harapaannya, dengan kegiatan ini dapat memberikan manfaat bagi mitra, dan semoga LP2M UMSU semakin berjaya, dan tetap konsisten dalam memberikan hibah/bantuan kepada para dosen dalam melaksanakan kegiatan pengabdian kepada masyarakat. Terima kasih juga kami ucapkan kepada Kepala Lingkungan X Kelurahan Suka Maju Kecamatan Medan Johordan ketua Remaja Masjid Assyafiiyah selaku mitra yang membersamai kami dalam kegiatan ini. Semoga kami tetap dapat menjalin hubungan kerja yang baik dengan para mitra. 


\section{DAFTAR PUSTAKA}

Anastasi, A. (2007). Tes Psikologi edisi ke 7 (Robertus Hariono S. Imam (ed.)). indeks.

Fanreza, R. (2016). Pendidikan Islam Dalam Pembentukan Karakter Anak Didik.

Fatmawaty, R. (2017). Memahami Psikologi Remaja. Jurnal Reforma, 2(1), 55-65. https://doi.org/10.30736/rfma.v6i2.33

Hurlock, Elizabeth, B. (1995). Psikologi Perkembangan. Erlangga.

Lubis, F. Y. (2008). Pengembangan Alat Ukur Minat untuk Pengembangan Karir pada Lulusan Sekolah Menengah Atas. Laporan Penelitian. . Bandung. Universitas Padjadjaran.

Ma'ruf, M., \& Ma'ruf, M. (2019). Pendidikan Islam Berbasis Kasih Sayang. Raheema, 4(2), 99-108. https://doi.org/10.24260/raheema.v4i2.838

Nasution, M., \& Sitepu, J. M. (2018). Dampak Pola Asuh Terhadap Perilaku Agresif Remaja Di Lingkungan X Kel Suka Maju Kec Medan Johor. Intiqad: Jurnal Agama Dan Pendidikan Islam, 10(1), 117-140. https://doi.org/10.30596/intiqad.v10i1.1927

Nur'aeni. (2012). Tes Psikologi: Tes Inteligensi dan Tes Bakat. Universitas Muhammadiyah Purwokerto Press.

Nurzannah, Akrim, M. Y. D. (2015). Studi Islam 1 Akidah dan Akhlak (A. lmran Sinaga, Junaidi, N. R. Amini, \& H. E. Samosir (eds.); 1st ed.). UMSU Press.

Sitepu, J. M. (2010). Peran Konsep Diri, Kompetensi Sosial, dan Program Belajar terhadap Koping Stress pada Remaja. Universitas Gajah Mada. 